\title{
Spain's National New Materials Program Sets Goals
}

Strategies and goals are being set for Spain's National Program for the Research and Development of New Materials. The program is one of 23 that integrate a National Plan for Scientific Research and Technological Development. The New Materials Program and five others (including microelectronics, photonics, space research, etc.) comprise the production and communication technologies area of the national plan. The New Materials Program will operate for an initial period of four years (19881991). Described here are the plans and actions that took place in the beginning months of 1988.

The New Materials Program will first aim to attack and solve some of the historic and endemic problems of Spanish industry and research centers in order to place them at a competitive level with their equivalents in the advanced European countries. This step is necessary to increase Spanish participation in the new materials projects of the European Community. Second, the program will pursue higher scientific and technological capabilities in specifically established priority areas.

Various strategies are planned to reach the following goals:

- Increasing the number of Spanish researchers and engineers. The number of Spanish researchers and engineers in materials was about 300 at the end of 1987. This figure appears low compared with the average of the European countries. Therefore, the New Materials Program, in coordination with the Program for Training for Research, proposes to increase that number through such actions as (1) the creation of new preand postdoctoral fellowships and grants (about 100 in 1988), (2) the recovery of Spanish scientists working in other countries, and (3) the interchange of foreign and Spanish scientists and of people from industry and research centers.

- Improving technical and bureaucratic support. One of the traditional problems of Spanish research centers and universities is a lack of technical and bureaucratic support (general equipment, mechanical, electronics, workrooms, services and so on). The New Materials Program will improve this situation through special budgets not connected with any particular research project, but addressed to strengthen the research substructure of teams, groups and departments.
- Stimulating collaborative R\&D. Research on materials has been traditionally accomplished by small groups (5-6 scientists). The New Materials Program is stimulating $R \& D$ projects that require not only the concentration of small groups but also collaborations between universities, research centers and private companies in order to reach a critical size in the number of scientists and also in facilities.

- Strengthening new materials industries. One of the program's most difficult problems is the lack of a strong industrial sector in both conventional and new materials fields. The program is focusing significant resources to increase the number of the innovative industries, the capacity of their R\&D groups, and their communication and collaboration with research centers and universities.

- Establishing R\&D priorities. Regarding the $R \& D$ priorities established in the New Materials Program, the national needs and the lines proposed in the European Programs (such as EURAM) have been taken into account. The following are some of the competing lines proposed:

1. Alloys and metallic materials (magnetic, high temperature resistant, ...)

2. Ceramic materials and glasses (electric, electronic, structural, ...)

3 . Polymeric materials (alloys, conductors, semiconductors, ...)

4. Composites (metallic, ceramic and organic matrices, ...)

5. Advanced materials (some semiconductors, high $\mathrm{T}_{c}$ superconductors, high ionic conductors, ...).

Several official organs are responsible for conducting different areas of the New Materials Program: the training and specialization action is headed by the General Direction of Scientific and Technical Research; the scientific research and special actions area is conducted by the General Secretary of the National Plan. (Both entities belong to the Ministry of Science and Education.) The technological development and innovation area is led by the Center of Industrial Development, which belongs to the Ministry of Industry. The fact that the responsibility for the program is distributed among three different entities has been criticized by scientists and industrialists.

The New Materials Program has led to an increase of $56 \%\left(1,900 \times 10^{\circ}\right.$ pesetas $)$ on the already existing funds $\left(3,400 \times 10^{\circ}\right.$ pesetas) for materials R\&D during 1988.

The new budget is distributed as follows:

Training and Specialization $198.5 \times 10^{\circ}$ pesetas

Scientific Research Projects and Structure

Industrial R\&D

$778.0 \times 10^{\circ}$ pesetas

General Funds

$900.0 \times 10^{6}$ pesetas

$23.5 \times 10^{6}$ pesetas

Prof. Carlos Sanchez

Universidad Autónoma de Madrid Member, New Materials Program

Commission

\section{Up Close Series}

\author{
Bring the significant \\ developments at your \\ institution to the attention \\ of your colleagues around \\ the world!
}

To submit an article or make a suggestion, contact:

Editor, MRS BULLETIN
Materials Research Society
9800 McKnight Road
Suite 327
Pittsburgh, PA 15237
Telephone (412) $367-3036$
Fax (412) 367-4373

